\title{
Peningkatan Kemampuan Dimensi Pengetahuan Konseptual Peserta didik melalui Penerapan Model Discovery Learning Terintegrasi media Pembelajaran KineMaster
}

\author{
Muhammad Asholahudin', Ismatullah Syichabudin², Dadang Daniswara Solihin ${ }^{3}$ \\ 1Universitas Sultan Ageng Tirtayasa, ${ }^{2}$ Dinas Pendidikan Kota Cilegon \\ ${ }^{3}$ LPMP Sumatera Selatan \\ E-mail: solahudinade35@gmail.com
}

\begin{tabular}{|c|c|}
\hline Article Info & Abstract \\
\hline Article History & This study aims to improve the ability of students in the dimensions of conceptual \\
\hline Received: 2021-09-20 & knowledge, improve the competence of principals and improve the ability of teachers \\
\hline $\begin{array}{l}\text { Revised: 2021-09-28 } \\
\text { Published: } 2021-11-02\end{array}$ & in the learning process. This research is a Classroom Action Research (CAR) with the \\
\hline & $\begin{array}{l}\text { implementation of two cycles in which, with a description of the stages of the research } \\
\text { consisting of, (1) Preparation; (2) Implementation; (3) Monev; (4) Reflection; (5) }\end{array}$ \\
\hline Keywords: & Follow-up using data collection techniques including interviews, documentation, \\
\hline $\begin{array}{l}\text { Knowledge; } \\
\text { Conceptual; }\end{array}$ & questionnaires and observations. The results showed that the application of the \\
\hline Model; & integrated discovery learning model with Kine Master learning media could improve \\
\hline $\begin{array}{l}\text { Discovery Learning; } \\
\text { KineMaster }\end{array}$ & the ability of students, improve the competence of principals and improve the ability of \\
\hline & $n$ the learnino procesc hy showing very well \\
\hline Artikel Info & Abstrak \\
\hline Sejarah Artikel & juan untuk meningkatkan kemampuan peserta didik dalam dimensi \\
\hline Diterima: 2021-09-20 & konseptual, meningkatkan kompetensi kepala sekolah dan meningkatkan \\
\hline $\begin{array}{l}\text { Direvisi: } 2021-09-28 \\
\text { Dinublikasi- } 2021-11-02\end{array}$ & kemampuan guru dalam proses pembelajaran. penelitian ini merupakan Penelitian \\
\hline & $\begin{array}{l}\text { Tindakan Kelas (PTK) dengan pelaksanaan dua siklus yang di dalamnya, dengan uraian } \\
\text { tahapan penelitian yang terdiri atas, (1) Persiapan; (2) Pelakasanaan; (3) Monev; (4) }\end{array}$ \\
\hline Kata kunci: & Refleksi; (5) Tindak lanjutdengan menggunakan teknik pengumpulan data diantaranya \\
\hline Pengetahuan; & adalah wawancara, dokumentasi, angket dan observasi. Hasil penelitian adalah \\
\hline Konseptual; & menunjukkan bahwa penerapan model discovery learning terintegrasi dengan media \\
\hline Discovery Le & pembelajaran Kine Master dapat meningkatkan kemampuan peserta didik, \\
\hline Kine Master. & $\begin{array}{l}\text { meningkatkan kompetensi kepala sekolah dan meningkatkan kemampuan guru dalam } \\
\text { proses pembelajaran dengan menunjukkan sangat baik. }\end{array}$ \\
\hline
\end{tabular}

\section{PENDAHULUAN}

Peraturan Menteri Pendidikan Nasional Nomor 13 Tahun 2007 tentang Standar Kepala Sekolah atau Madrasah telah menetapkan bahwa ada 5 (lima) dimensi kompetensi yang perlu dimiliki kepala sekolah, diantaranya (1) Kepribadian; (2)Manajerial; (3)Kewirausahaan; (4)Supervisi; dan (5)Sosial. Sejalan dengan semakin meningkatnya tuntutan masyarakat terhadap akuntabilitas sekolah, maka meningkat pula tuntutan terhadap para kepala sekolah, mereka diharapkan mampu melaksanakan fungsinya baik sebagai manager dan leader di sekolah dalam upaya meningkatkan mutu pendidikan, Kepemimpinan kepala sekolah adalah cara atau usaha kepala sekolah dalam mempengaruhi, mendorong, membimbing, mengarahkan, dan menggerakkan guru, staf, siswa, orang tua siswa dan pihak lain yang terkait untuk bekerja atau berperan serta dalam usaha mencapai tujuan yang telah ditetapkan. Kepala sekolah sebagai seorang pemimpin tentunya akan memiliki kemampuan atau kecakapankecakapan yang mendukung kemampuannya sebagai seorang pemimpin di sekolah seperti kemampuan berkomunikasi yang baik, memiliki kemampuan teknis dalam bidangnya, memiliki kemampuan analitis yang tajam, bersikap tegas dan berani mengambil keputusan, etos kerjanya tinggi dan memiliki visi yang jelas, disamping itu, kepala sekolah juga dituntut untuk membina dan mengelola seluruh komponen sekolah lainnya sesuai dengan Standar Nasional Pendidikan (SNP) dan Standar Pelayanan Minimal (SPM).

Begitu besar beban dan tanggung jawab seorang kepala sekolah, maka untuk menjadi seorang kepala sekolah yang profesional tentu tidaklah mudah. Peraturan menteri pendidikan dan kebudayaan nomor 6 tahun 2018 tentang penugasan guru sebagai kepala sekolah telah mengatur bahwa guru yang diberikan tugas tambahan sebagai kepala sekolah harus memiliki kompetensi yang di persyaratkan. Untuk mencapai kompetensi tersebut calon kepala 
sekolah maka terlebih dahulu seorang calon kepala sekolah dibekali dengan pendidikan dan pelatihan calon kepala yang merupakan kegiatan pemberian pengalaman pembelajaran teoretik maupun praktik yang bertujuan untuk menumbuh kembangkan pengetahuan, sikap dan keterampilan pada dimensi-dimensi kompetensi kepribadian, manajerial, kewirausahaan, supervisi, dan sosial. Pelatihan, pembimbingan dan pembinaan bagi calon kepala sekolah merupakan upaya-upaya yang mesti dilakukan oleh pemerintah dalam rangka melahirkan pemimpin sekolah yang berkualitas yang diharapkan mampu untuk memimpin dan mengelola sekolah dalam upaya meningkatkan mutu pendidikan.

Dengan pengetahuan dan keterampilan yang mumpuni tentang pendidikan, kepala sekolah diharapkan dapat dengan mudah mencapai visi, misi, dan tujuan sekolah yang telah di tetapkan. Sesuai dengan amanat Peraturan Menteri Pendidikan Nasional Nomor 13 Tahun 2007 tentang Standar Kepala Sekolah/ Madrasah menetapkan 5 (lima) dimensi kompetensi yaitu:
(1) kepribadian;
(2) manajerial;

kewirausahaan; (4) supervise; dan (5) sosial. Dasar kompetensi kepribadian ini akan sangat menentukan kompetensi lainnya, khususnya dalam melaksanakan program pendidikan nasional. Sebagai tambahan pengetahuan dan keilmuan dalam bidang perencanaan dan pelaksanaan program pendidikan, kepala sekolah harus mampu menunjukkan kinerjanya berdasarkan kebijakan, perencanaan, dan program pendidikan.

Dalam rangka meningkatkan mutu kepala sekolah/ madrasah, pemerintah mengeluarkan Peraturan Menteri Pendidikan dan Kebudayaan (Permendikbud) nomor 6 Tahun 2018, tentang Penugasan Guru sebagai Kepala Sekolah atau Madrasah sebagai pengganti Permendiknas nomor 28 tahun 2010 tentang Penugasan Guru sebagai Kepala Sekolah atau Madrasah, Permendikbud No 6 Tahun 2018 ini memuat sistem penyiapan calon kepala sekolah atau madrasah, proses pengangkatan kepala sekolah atau madrasah, masa tugas, Pengembangan Keprofesian Berkelanjutan (PKB), penilaian kinerja kepala sekolah atau madrasah, mutasi dan pemberhentian tugas guru sebagai kepala sekolah atau madrasah.

Kepala sekolah sejatinya harus menjadi pendidik yang mampu membina guru-guru di sekolahnya sehingga menjadi guru kreatif dan inovatif dalam pembelajaran. Selain itu, kepala sekolah tidak hanya dituntut untuk membina guru saja, akan tetapi lebih dari itu, juga dituntut untuk membina dan mengelola seluruh komponen sekolah lainnya, seperti tenaga adminstrasi sekolah, tenaga perpustakaan, dan tenaga pembantu lainnya. Disisi lain, tujuan utama sekolah berupa peningkatan mutu pendidikan hanya dapat diraih jika seluruh komponen sekolah dapat melaksanakan tugas pokok dan fungsinya masing-masing melalui pembinaan dan pengelolaan seorang kepala sekolah yang professional sehingga tercapai school wellbeing.

Pendidikan dan pelatihan yang dijalani calon kepala sekolah dalam kegiatan tatap muka (In Service Training 1(IST 1) dalam kurun waktu 70 jam merupakan modal awal untuk menjalani praktik lapangan On The Job Training 2 (OJT 2) selama kurang lebih 2 bulan. Kegiatan OJT 2 penting bagi peserta diklat untuk mempraktikkan kompetensi yang telah dipelajari selama kegiatan tatap muka. Dalam OJT 2 dipraktikkan bagaimana melakukan Rencana Proyek Kepemimpinan (RPK).

Ada beberapa penelitian yang serupa pada penelitian ini diantaranya, (Amelia. V dan Arwin, 2020) Mengembangkan Media Pembelajaran Berbasis Aplikasi Kinemaster Pada Pembelajaran Tematik Terpadu di Kelas III Sekolah Dasar, kemudian (Khaira dam Hafizatul. 2021) Memanfaatkan Aplikasi Kinemaster Sebagai Media Pembelajaran Berbasis ICT. Selanjutnya (Salahuddin dan Husein, 2020) meneliti tentang Efektivitas Video Animasi Berbasis Kinemaster Untuk Meningkatkan Penguasaan Kosakata Bahasa Arab Siswa Kelas Viii Di Mts. Nurul Huda Ketambul, Tuban. Terakhir oleh (Khaira H.. 2021) meneliti tentang media pembelajaran audio visual berbasis aplikasi kinemaster. Dari penelitian sebelumnya terdapat perbedaan diantaranya, meningkatkan kemampuan dimensi pengetahuan konseptual peserta didik dan menerapkan Model Discovery Learning.

Adapun Berdasarkan hasil analisis rapor mutu SMP Negeri 6 Cilegon tahun 2020 diperoleh kesimpulan bahwa masalah utama yang menjadi perhatian khusus dalam perencanaan program sekolah adalah belum memiliki kemampuan pengetahuan konseptual yang diinginkan, Berdasarkan kajian masalah tentang Standar Kompetensi Lulusan yang fokusnya dimensi pengetahuan, maka penulis akan mengadakan program tentang "Peningkatan Kemampuan Dimensi Pengetahuan Konseptual Peserta Didik 
Melalui Penerapan Model Discovery Learning Terintegrasi Media Pembelajaran Kine Master.

Menurut Handoko (2021) Kine Master adalah sebuah aplikasi penyuntingan video berbasis perangkat bergerak dengan konsep bebas digunakan atau berlangganan. Sedangkan menurut Haryudin (2021) Kine Master is a mobile application specifically designed to help Android and iOS users modify videos from ordinary videos to more interesting videos, Menurut Fajariyah (2017) memberikan uraian mengenai langkah-langkah menggunakan KineMaster untuk pembuatan cerita digital sebagai berikut: membuat proyek baru, memasukkan visuals/video dari media browser, memasukkan audio (recording atau file), memberikan efek dan menyunting timeline, menyimpan video, pada langkah terakhir menyimpan video bisa dimasukkan ke dalam beberapa sumber.

Pengetahuan konseptual meliputi kategori dan klasifikasi, serta hubungan keduanya. Pengetahuan konseptual memuat skema-skema, model-model, atau teori-teori eksplisit dan implisit dalam model-model psikologi kognitif yang berbeda. Pengetahuan konseptual dibagi menjadi tiga jenis: pertama, pengetahuan klasifikasi dan kategori(meliputi kategori, kelas, pembagian,dan penyusunan spesifik yang digunakandalam pokok bahasan yang berbeda), kedua, pengetahuan dasar dan umum (meliputi abstraksi nyata yang menyimpulkan fenomena dalam penelitian), ketiga pengetahuan teori, model,dan struktur (meliputi pengetahuan mengenai prinsip dan generalisasi dengan hubungan yang jelas dengan menyajikan pandangan sistemis dan jelas mengegani suatu fenomena, masalah, atau poko bahasan.

Model discovery learning adalah salah satu model yang digunakan dalam proses pembelajaran agar peserta didik dapat memahami konsep atau pengertian serta hubungannya melalui proses intuitif dengan cara melakukan observasi, klasifikasi, pengukuran, prediksi,dan penentuan sehingga akan sampai kepada kesimpulan.

\section{METODE PENELITIAN}

Metode penelitian ini menggunakan Penelitian Tindakan Kelas (PTK) dengan pelaksanaan dua siklus yang di dalamnya terdapat point diantarnya, (1) Persiapan; (2) Pelakasanaan; (3) Monev; (4) Refleksi; (5) Tindak lanjut. Pada alat pengumpulan data menggunakan intrument wawancara, angket dan observasi. Menurut menyatakan PTK merupakan kegiatan mencermati suatu objek dengan menggunakan aturan-aturan tertentu untuk memperoleh informasi yang bermanfaat dan bertujuan untuk memperbaiki atau meningkatkan mutu praktek pembelajaran

\section{HASIL DAN PEMBAHASAN}

\section{A. Siklus Pertama}

1) Persiapan

a) Pertemuan dengan kepala sekolah dan guru

Pada tanggal 13 September 2021 hari Senin, calon kepala sekolah melakukan diskusi dan sekaligus melaporkan kegiatan-kegiatan tahapan dalam diklat calon kepala sekolah. calon kepala sekolah memberikan informasi terkait tugas yang diberikan dalam 0JT-2 ke kepala sekolah. selanjutnya kepala sekolah memberikan arahan-arahan agar tugas dalam diklat calon kepala sekolah dilaksanakan dengan maksimal.

b) Mensosialisasikan kegiatan CKS tentang RPK dan PK.

Setelah melakukan pertemuan dengan kepala sekolah, selanjutnya calon kepala sekolah mengadakan sosialisasi dengan warga sekolah terkait kegiatan RPK dan PK. Dalam sosialisasi diberikan gambaran terkait adanya guru model, supervisor dan monev untuk membantu kegiatan RPK.

c) Menyusun Program Peningkatan Kemampuan Peserta Didik.

Calon kepala sekolah menyusun program kegiatan RPK agar berjalan dengan lancar dan tertib.

d) Menyusun Jadwal Kegiatan

Calon kepala sekolah menyusun jadwal pelaksanaan RPK agar dapat berjalan dengan tertib dan lancar.

e) Menyusun RPP

Calon kepala sekolah dengan guru model melakukan forum discussion group (FGD) untuk membuat RPP sebanyak 2 (dua) siklus dan rencana pelaksanaan pembelajaran.

f) Menyiapkan media pembelajaran KINE MASTER

Calon kepala sekolah dan guru model menyiapkan materi pembelajaran tentang Descriptive text dan Introducing Our selves dengan mencari dari youtobe tentang pembelajaran Kine Master. 
g) Menyiapkan instrumen supervisi dan MONEV

Calon kepala sekolah menyiapkan intrumen-instrumen yang dibutuhkan untuk pelaksanaan RPK, diantaranya adalah :

1. Intrumen Perencanaan Kegiatan Pembelajaran.

2. Intrumen Pengamatan Pembelajaran.

3. Instrumen Evaluasi Hasil Kegiatan

4. Instrumen Pencapaian Students Wellbeing.

5. Instrumen Peningkatan Kompetensi Kepala Sekolah Berdasarkan Hasil AKPK.

6. Instrumen Monitoring Pelaksanaan Kegiatan.

2) Pelaksanaan

a) Guru Model Pertama

Kegiatan Rencana Proyek Kepemimpinan (RPK) dilaksanakan pada tanggal 27 September 2021 pada pukul 08.00 s.d 09.30 WIB di kelas VII A dengan guru model Ibu Mutoyibah, S.Pd.I dengan mengajarkan tentang materi Descriptive Text. Dalam pelaksanaan kegiatan proses pembelajaran yang melakukan suervisor adalah Ibu Dra. Nur'aini, dalam proses pembelajaran guru model Ibu Mutoyibah sangat aktif dalam mengajar, sehingga peserta didik juga sangat antusias dalam belajar di kelas. Apalagi proses pembelajaran menggunakan media Kinemaster. Media Kinemaster merupakan salah satu media yang tepat untuk pembelajaran di kelas. Dengan menggunakan media Kinemaster peserta didik dapat memahami apa yang ditayangkan. Peserta didik bisa mendengar sekaligus membaca apa yang muncul dalam layar. Dengan demikian peserta didik juga dapat memahami materi pelajaran dengan baik.

b) Guru Model kedua

Kegiatan Rencana Proyek Kepemimpinan (RPK) dilaksanakan pada tanggal 30 September 2021 pada pukul 08.00 s.d 09.30 WIB di kelas VII C dengan guru model Bapak Suhanda Wijaya, S.Pd. dengan mengajarkan tentang materi introducing our selves. Dalam pelaksanaan kegiatan proses pembelajaran yang melakukan supervisor adalah Ibu Dra. Nur'aini, dalam proses pembelajaran guru model Bapak Suhanda Wijaya, S.Pd. sangat aktif dalam mengajar, sehingga peserta didik juga sangat antusias dalam belajar di kelas. Apalagi proses pembelajaran menggunakan media Kinemaster, media Kinemaster merupakan salah satu media yang tepat untuk pembelajaran di kelas, dengan menggunakan media Kinemaster peserta didik dapat memahami apa yang ditayangkan. Peserta didik bisa mendengar sekaligus membaca apa yang muncul dalam layar. Dengan demikian peserta didik juga dapat memahami materi pelajaran dengan baik. Untuk hasil belajar peserta didik dalam siklus pertama ini:

1. Kelas VII A

Dalam proses pembelajaran, peserta didik dalam mengerjakan tugas yang diberikan dapat berjalan dengan lancar dan selesai sesuai dengan waktu yang diberikan. Ketika diberikan penugasan setelah proses pembelajaran, setelah dinilai dari 16 (enam belas ) peserta didik, yang mendapatkan nilai di atas KKM sebanyak 13 (tiga belas) peserta didik, sedangkan yang mendapatkan nilai di bawah KKM sebanyak 3 (tiga) peserta didik.

2. Kelas VII C

Dalam proses pembelajaran, peserta didik dalam mengerjakan tugas yang diberikan dapat berjalan dengan lancar dan selesai sesuai dengan waktu yang diberikan. Ketika diberikan penugasan setelah proses pembelajaran, setelah dinilai dari 16 (enam belas ) peserta didik, yang mendapatkan nilai di atas KKM sebanyak 14 (empat belas) peserta didik, sedangkan yang mendapatkan nilai di bawah KKM sebanyak 2 (dua) peserta didik.

3) Monev

Dalam kegiatan monitoring dan evaluasi siklus pertama, beberapa kegiatan diantaranya adalah sebagai berikut:

a) Memantau dan Menilai Pelaksanaan Monitoring terkait Pelaksanaan kegiatan RPK

Setelah melakukan pembelajaran siklus pertama, guru monev melakukan 
pemantauan dan menilai hasil kegiatan siklus pertama. Guru monev melakukan pengisian intrumen sesuai data yang ada di lapangan.

b) Menentukan Hasil Monev kegiatan RPK Hasil Monev siklus pertama ada di lampiran.

c) Menentukan Dampak dari kegiatan RPK Selanjutnya, guru monev melihat dampak keberhasilan kegiatan RPK melalui instrumen yang diisi oleh kepala sekolah, guru dan peserta didik. Hasil ini ada di lampiran.

4) Refleksi

Kegiatan refleksi yaitu menanyakan hal-hal terkait pelaksanaan siklus pertama untuk perbaikan siklus kedua. Diantaranya adalah :

a) Penyusunan RPP hendaknya dilengkapi dengan metode dan pendekatan.

b) Dalam kegiatan pendahuluan hanya menyampaikan tujuan pembelajaran. Kompetensi, indikator dan alokasi waktu belum dijelaskan.

c) Guru model tidak menulis di papan tulis.

d) Guru model masih banyak menjelaskan teori.

5) Tindak Lanjut

Setelah melihat hasil dari guru supervisor, guru monev, dan refleksi, maka pelaksanaan pembelajaran pada siklus kedua akan fokus kepada hal-hal yang masih kurang terutama penyusunan RPP dan Pelaksanaan Pembelajaran.

\section{B. Siklus kedua}

1) Persiapan

Kegiatan- kegiatan dalam pembelajaran siklus kedua ini yang terkait pelaksanaan diantaranya adalah:

a) Pertemuan dengan guru model, guru supervisor dan guru monev

Kegiatan ini diawali dengan diskusi untuk melakukan analisa kembali terkait pelaksanaan pembelajaran siklus pertama, dalam pertemuan ini selanjutnya mencatat dan fokus terkait kekurangan dalam proses pembelajaran siklus pertama.

b) Menyusun Jadwal kegiatan

Menyusun jadwal kegiatan proses pembelajaran agar semua pihak yang terlibat bisa mempersiapkan dengan maksimal. c) Menyusun Perbaikan RPP

Penyusunan perbaikan RPP dilakukan dari hasil telaah RPP yang dilkukan oleh guru supervisor.

d) Menyiapkan media pembelajaran

Kinemaster

Untuk meaningful dan joyful learning guru model menyiapkan media pembelajaran Kinemaster, media Kinemaster dicari yang simple dan menarik agar peserta didik bisa memahami dengan menyeluruh.

2) Pelaksanaan

a) Guru Model Pertama

Guru model pertama yaitu Bapak Suhanda Wijaya, S.Pd melakukan pembelajaran pada siklus kedua pada hari Jum'at tanggal 1 Oktober 2021 pada jam 08.00 s.d 09.30 WIB, dalam proses pembelajaran guru model Bapak Suhanda Wijaya, S.Pd. sangat aktif dalam mengajar, sehingga peserta didik juga sangat antusias dalam belajar di kelas. Apalagi proses pembelajaran menggunakan media Kinemaster. Media Kinemaster merupakan salah satu media yang tepat untuk pembelajaran di kelas. Dengan menggunakan media Kinemaster peserta didik dapat memahami apa yang ditayangkan. Peserta didik bisa mendengar sekaligus membaca apa yang muncul dalam layar. Dengan demikian peserta didik juga dapat memahami materi pelajaran dengan baik.

b) Guru Model Kedua

Guru model kedua dalam pelaksanaan proses pembelajaran siklus kedua pada hari Kamis tanggal 30 September 2021 pada pukul 08. 00 s.d 09.30 WIB.

Dalam proses pembelajaran guru model Ibu Mutoyibah, S.Pd.I sangat aktif dalam mengajar, sehingga peserta didik juga sangat antusias dalam belajar di kelas, apalagi proses pembelajaran menggunakan media Kinemaster. Media Kinemaster merupakan salah satu media yang tepat untuk pembelajaran di kelas. Dengan menggunakan media Kinemaster peserta didik dapat memahami apa yang ditayangkan. Peserta didik bisa mendengar sekaligus membaca apa yang muncul dalam layar. Dengan demikian peserta didik juga dapat memahami materi pelajaran 
dengan baik. Untuk hasil belajar peserta didik dalam siklus kedua ini :

1. Kelas VII A

Dalam proses pembelajaran, peserta didik dalam mengerjakan tugas yang diberikan dapat berjalan dengan lancar dan selesai sesuai dengan waktu yang diberikan. Ketika diberikan penugasan setelah proses pembelajaran, setelah dinilai dari 16 (enam belas) peserta didik, semua peserta didik mendapatkan nilai di atas KKM.

2. Kelas VII C

Dalam proses pembelajaran, peserta didik dalam mengerjakan tugas yang diberikan dapat berjalan dengan lancar dan selesai sesuai dengan waktu yang diberikan. Ketika diberikan penugasan setelah proses pembelajaran, setelah dinilai dari 16 (enam belas) peserta didik, semua peserta didik mendapatkan nilai di atas KKM.

3) Monev

Dalam kegiatan monitoring dan evaluasi siklus pertama, beberapa kegiatan diantaranya adalah sebagai berikut:

a) Memantau dan Menilai Pelaksanaan Monitoring terkait Pelaksanaan kegiatan RPK

Setelah melakukan pembelajaran siklus pertama, guru monev melakukan pemantauan dan menilai hasil kegiatan siklus pertama. Guru monev melakukan pengisian intrumen sesuai data yang ada di lapangan.

b) Menentukan Hasil Monev kegiatan RPK Hasil Monev siklus kedua ada di lampiran.

c) Menentukan Dampak dari kegiatan RPK Selanjutnya, guru monev melihat dampak keberhasilan kegiatan RPK melalui instrumen yang diisi oleh kepala sekolah, guru dan peserta didik. Hasil ini ada di lampiran.

4) Refleksi

Dalam kegiatan refleksi menanyakan halhal yang sudah difahami atau belum terkait proses pembelajaran yang sudah dilakukan.

\section{SIMPULAN DAN SARAN}

\section{A. Simpulan}

Media pembelajaran Kinemaster dapat meningkatkan kemampuan pengetahuan konseptual peserta didik diintegrasikan dengan model discovery learning, calon kepala sekolah dapat meningkatkan kompetensinya, dan guru dapat meningkatkan kemampuan proses pembelajaran di dalam kelas.

\section{B. Saran}

Bagi calon kepala sekolah agar dapat meningkatkan kompetensinya dengan selalu melakukan pendalaman keilmuan dan praktik di lapangan. Kegiatan Rencana Proyek kepemimpinan bagi guru hendaknya disambut baik untuk meningkatkan kualitas pembelajarannya.

\section{DAFTAR RUJUKAN}

Amelia, V., \& Arwin, A. (2021). Pengembangan Media Pembelajaran Berbasis Aplikasi Kinemaster Pada Pembelajaran Tematik Terpadu di Kelas III Sekolah Dasar. Jurnal Inovasi Pendidikan dan Pembelajaran Sekolah Dasar, 4(2), 88-97.

Arsyad, Azhar. 2014. Media Pembelajaran. Jakarta : PT RajaGrafindo Persada.

Aunurrahman, Mifta Rahman, \& Purwaningsih, D. I. (2021). Analisis Penggunaan Google Classroom sebagai Media Pembelajaran. JIIP - Jurnal Ilmiah Ilmu Pendidikan, 4(6), 445-449. Retrieved from

Haryudin. 2021. The Utilization of Kinemaster applications in the making of multimedia based teaching materials for English ELearning in new normal (Covid-19). Jurnal Project (profesional jurnal of english education) hal 341-352

JIIP, R. (2018). Hastuti (Penerapan Model Pembelajaran Guided Discovery Learning (GDL)): Penerapan Model Pembelajaran Guided Discovery Learning (GDL) untuk Meningkatkan Hasil Belajar Siswa Kelas XI-ATPH SMKN 1 Woja. JIIP - Jurnal Ilmiah Ilmu Pendidikan, 1(2), 73-80. Retrieved from http://jiip.stkipyapisdompu.ac.id/jiip/in dex.php/JIIP/article/view/12

Kemendikbud. 2021. Rencana Tindak Lanjut. Jakarta : Direktorat Pendidikan Profesi 
dan Pembinaan Guru dan Tenaga Kependidikan.

Khaira, H. (2021, October). MEDIA PEMBELAJARAN AUDIO VISUAL BERBASIS APLIKASI KINEMASTER. In Prosiding Seminar Nasional (Vol. 1, No. 1).

Khaira, Hafizatul (2021) Pemanfaatan Aplikasi Kinemaster Sebagai Media Pembelajaran Berbasis ICT. Prosiding Seminar Nasional Pembelajaran Bahasa dan Sastra Indonesia (SemNas PBSI) - 3. pp. 39-44. ISSN 978-623-6984-07-9

Nurgiansah, T. H., Pratama, F. F., \& Nurchotimah, A. S. I. (2021). Penelitian Tindakan Kelas Dalam Pendidikan Kewarganegaraan. Jurnal Pendidikan PKN (Pancasila dan Kewarganegaraan), 2(1), 10-23.

Ratmaningsih, Ni Made. 2019. Metode dan Strategi Pembelajaran Bahasa Inggris. Jakarta : PT RajaGrafindo Persada

Salahuddin, Husein (2020) EFEKTIVITAS VIDEO ANIMASI BERBASIS KINEMASTER UNTUK MENINGKATKAN PENGUASAAN KOSAKATA BAHASA ARAB SISWA KELAS VIII DI MTS. NURUL HUDA KETAMBUL, TUBAN. Undergraduate (S1) thesis, Universitas Muhammadiyah Malang.
Sumarni. (2020). Integrasi sarana belajar Daring berbasis Edmodo, Whatsapp dan Youtube Channel terhadap Evektifitas pembelajaran Era New Normal. JIIP Jurnal Ilmiah Ilmu Pendidikan, 3(3), 672676. Retrieved from

Suryani, Nunuk, dkk. 2019. Media Pembelajaran Inovatif dan Pengembangannya. Bandung : PT. Remaja Rosdakarya.

2021. Coaching Dalam Supervisi Guru dan Tenaga Kependidikan. Jakarta : Direktorat Pendidikan Profesi dan Pembinaan Guru dan Tenaga Kependidikan

2021. Manajerial Sekolah. Jakarta : Direktorat Pendidikan Profesi dan Pembinaan Guru dan Tenaga Kependidikan

2021. Pembentukan Karakter Kepala Sekolah. Jakarta : Direktorat Pendidikan Profesi dan Pembinaan Guru dan Tenaga Kependidikan

2021. Pengembangan Kewirausahaan. Jakarta : Direktorat Pendidikan Profesi dan Pembinaan Guru dan Tenaga Kependidikan. 